\title{
Pelaksanaan Yurisdiksi Universal Terhadap Modern Piracy Jure Gentium
}

\author{
Nadiyah Asfarosya
}

nadiyah17001@mail.unpad.ac.id

\author{
Magister Hukum Fakultas Hukum Universitas Padjadjaran
}

\begin{abstract}
This study aims to analyze the relevance of the approach of universal jurisdiction in law enforcement against the crime of modern pirates. This study looks at piracy itself which changes over time and the effectiveness of universal jurisdiction in minimizing back piracy that can affect the international community. This research is normative. Universal jurisdiction has long been in law enforcement against piracy. However, turning the numbers of countries implementing universal jurisdiction raises the question of what constitutes an obstacle to implementing universal jurisdiction over the crime of piracy. In addition, several solutions have emerged that are considered more effective in enforcing the law against modern piracy in order to prevent the culture of impunity.
\end{abstract}

Keywords: Piracy Jure Gentium, Universal Jurisdiction, Law Enforcement

\section{Pendahuluan}

Salah satu kejahatan yang tunduk pada yurisdiksi universal adalah piracy jure gentium. Pembajakan di laut (piracy), bisa dibilang kejahatan internasional tertua. Pembajakan maritim mulai muncul kembali sekitar dua dekade lalu, sebagian besar di lepas pantai Somalia, dengan demikian menghadirkan masalah ekonomi, keamanan dan kemanusiaan yang besar. Sudah seharusnya negara-negara bekerja sama untuk memberantas maraknya aksi bajak laut saat ini mengingat kerugian yang ditimbulkan tidaklah sedikit jika dibiarkan terus menerus.

Sekitar 90 persen perdagangan dunia beroperasi lintas laut dan jumlah ini akan terus meningkat kedepannya. Perdagangan lintas laut sangat rentan terhadap serangan bajak laut karena kuantitas kargo yang terlibat, tenaga kerja internasional yang beragam dan besar, kesulitan penegakan hukum baik di pelabuhan dan di laut, dan lingkungan peraturan yang buruk dari pelayaran internasional dengan rendahnya tingkat akuntabilitas, rumitnya permasalahan kepemilikan, dan tingginya insiden dokumentasi penipuan. Bajak laut berpotensi mengeksploitasi kelemahan ini untuk menggunakan transportasi laut untuk tujuan jahat, atau untuk melancarkan serangan terhadap infrastruktur pengiriman dan pelabuhan yang dapat menyebabkan gangguan ekonomi besar-besaran. ${ }^{1}$ Pembajakan juga secara signifikan membatasi pengiriman bantuan makanan ke

\footnotetext{
${ }^{1}$ Sam Bateman "Outlook; The New Threat of Maritime Terrorism" in Lloyd's Marine Intelligence Unit, Violace at Sea, Routledge, USA, 2007, hlm. 241
} 
Somalia yang dilanda kekeringan, yang pada akhirnya mengakibatkan ribuan kematian. ${ }^{2}$

Mengenai definisi dari piracy itu sendiri, pada masa yunani kuno istilah bajak laut mengacu pada siapapun yang melakukan penyerangan melalui laut, dan masih menjadi bagian dari perang. ${ }^{3}$ Namun dalam definisi bajak laut modern, Pembajakan adalah kejahatan internasional yang melibatkan tindakan kekerasan, penahanan kapal, atau penyerangan oleh awak atau penumpang kapal pribadi terhadap kapal lain, orang, atau properti di atas kapal, ketika berada di perairan

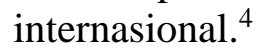

Definisi hukum pembajakan telah berfluktuasi selama berabad-abad dilihat dari metode para pelaku dan kekuatan negara. Sifat kejam dari bajak laut membuat bajak laut tunduk pada yurisdiksi universal, tetapi apa yang merupakan tindakan itu sendiri berkisar dari perampokan langsung di laut, kepada yang dikenal baru-baru ini yaitu tren modern menggunakan definisi "serangan kekerasan di laut" yang luas dan sangat menarik karena kemampuannya untuk menjelaskan berbagai perilaku dalam berbagai konteks yang luas. ${ }^{5}$

Yurisdiksi dalam menegakkan piracy yang diakui dalam hukum internasional adalah yurisdiksi universal. ${ }^{6}$ Pembajakan merupakan tindak pidana pertama yang tunduk dalam yurisdiksi universal. Bahkan

2 Michael Scharf and Mistale Taylor, "A Contemporary Approach to the Oldest International Crime", Utrecht Journal of International and European Law, hlm 78.

${ }^{3}$ Yitiha Simbeye, Yitiha Simbeye, Immunity and International Criminal Law, Ashgate Publishing Limited, USA, 2004, hlm. 42

4 Nerea Marteache and Gisela Bichler, Crime Prevention and Transportation System in Crime Prevention, CRC Press, New York, 2017, hlm. 83

5 Michael J. Kelly, "The Pre-History of Piracy as a Crime \& Its Defitional Odyssey", Case Western Reserve Journal of International Law, Vol. 46, Issues 1\&2, 2013, hlm. 26

6 Ilias Bantekas and Susan Nash, International Criminal Law, $2^{\text {nd }}$ edition, Cavendish Publishing, Australia, 2003, hlm. 154 dapat dikatakan bahwa prinsip yurisdiksi universal lahir pertama kali disebabkan karena adanya keinginan dari negara-negara untuk menindak kejahatan pembajakan yang dilakukan di laut lepas. Dengan adanya prinsip universalitas ini setiap negara berhak untuk menangkap perompak di laut lepas dan menghukum mereka tanpa memandang kebangsaan serta tempat dilakukannya kejahatan tersebut. ${ }^{7}$

Akan tetapi, dalam praktiknya untuk keseluruhan kasus pembajakan sejak tahun 1998-2009 berjumlah 1158 kejadian pembajakan, pelaksanaan yurisdiksi universal oleh negara-neagra terjadi tidak lebih dari 1,47 persen atau hanya sekitar 17 penuntutan. $^{8}$ Tentunya menuai pertanyaan mengapa yurisdiksi yang lahir dari adanya kejahatan bajak laut justru di masa sekarang dapat dikatakan kurang efektif dalam mengatasi adanya fenomena bajak laut ini. Bahkan, dalam beberapa kasus terjadi peristiwa "catch and release", dimana negara-negara yang telah menangkap bajak laut ini pada akhirnya membebaskan mereka.

Adanya peristiwa ini bukannya tanpa alasan, tentu saja terdapat alasan mengapa yrisdiksi universal sekarang terkesan sangat sulit untuk dilaksanakan terhadap kejahatan pembajakan di laut, yang akan diuraikan lebih lanjut dalam paper ini. Selain itu, sulitnya pelaksanaan yurisdiksi universal membuat para ahli untuk memikirkan alternatif lain dalam menghadapi para bajak laut. Hal ini juga dilakukan mengingat konsep dan definisi piracy yang berubah dari waktu ke waktu, sehingga para ahli mencoba mencari alternatif yang dianggap relevan dalam penegakan hukum terhadap bajak laut ini. Dikarenakan adanya peristiwa ini penulis tertarik untuk meneliti mengenai

${ }^{7}$ J.G. Starke, J.G. Starke, Pengantar Hukum Internasional, edisi kesepuluh, Jakarta, Sinar Grafika, 2003, hlm. 3

${ }^{8}$ Eugene Kontorovich and Steven Art, "An Empirical Examination Of Universal Jurisdiction For Piracy", The American Journal of International Law, Vol. 104, No. 3, 2010, hlm. 436 
Pelaksanaan Yurisdiksi Universal

\section{Terhadap Modern Piracy Jure Gentium.}

Rumusan masalah penelitian ini terdiri dari 2 (dua) bagian yaitu sebagai berikut: Pertama, bagaimanakah perkembangan definisi piracy jure gentium dari masa ke masa? Kedua, apakah pelaksanaan yurisdiksi universal masih dibutuhkan dalam kejahatan modern piracy jure gentium?

\section{Metode Penelitian}

Jenis penelitian yang digunakan adalah penelitian hukum normatif yaitu penelitian hukum kepustakaan, karena menjadikan bahan kepustakaan sebagai tumpuan utama. ${ }^{9}$ Dalam penelitian hukum normatif ini penulis melakukan penelitian terhadap sinkronisasi hukum yang bertitik tolak dari bidang-bidang tata hukum pidana internasional, dengan cara mengadakan identifikasi terlebih dahulu terhadap kaidahkaidah hukum yang berlaku dalam hukum kebiasaan internasional dan traktat internasional, juga pendapat para ahli hukum. ${ }^{10}$

\section{Hasil Penelitian}

\section{A. Perkembangan Konsep Piracy Jure Gentium dalam Hukum Internasional}

Piracy dalam hukum internasional, atau yang lebih dikenal dengan Piracy jure gentium, merupakan salah satu pelanggaran internasional yang tertua. ${ }^{11}$ Mengutip dari J.A Gottschalk et.al menyatakan bahwa "the very first time something valuable was known to be leaving a beach on a raft the first pirate was around to steal it". ${ }^{12}$ Pernyataan ini menggambarkan betapa tua kejahatan ini, bahkan beberapa ahli mengumpamakan

9 Soerjono Soekanto, Sri Mamudji, Penelitian Hukum Normatif, Suatu Tinjauan Singkat, PT. Raja Grafindo, Jakarta: 2003, hlm 23

hlm. 95

11 Ilias Bantekas and Susan Nash, Op.cit,

\footnotetext{
${ }^{12}$ Michael J. Kelly, Op.cit, hlm. 28
}

bajak laut telah ada sejak manusia pertama berlayar. Terlepas dari telah begitu lama kejahatan ini dikenal secara luas, kejahatan pembajakan di laut masih berlangsung sampai sekarang, dan sejak zaman Grotius, seorang bajak laut dianggap sebagai hostis humanis generis, musuh bagi umat manusia. $^{13}$

Mengenai definisi dari piracy itu sendiri, pada masa yunani kuno istilah bajak laut mengacu pada siapapun yang melakukan penyerangan melalui laut, dan masih menjadi bagian dari perang. ${ }^{14}$ Dulunya di Inggris hingga Statuta Henry VIII 1536, pembajakan hanya dihukum di inggris ketika dilakukan dalam ranah Admiralty of the Crown dan hanya sebagai pelanggaran sipil. Selain itu, dahulunya juga secara umum diketahui bahwa siapa pun yang mencuri dilaut disebut seorang bajak laut. Namun, Sir Charles Hedges, seorang hakim di High Court of Admiralty, memberi definisi yang sedikit berbeda yaitu bahwa "pembajakan (piracy) adalah istilah lain dari perampokan (robbery) di laut". ${ }^{15}$

$\begin{gathered}\text { Secara } \\ \text { perdagangan }\end{gathered}$ historis,
maritim berkembang, semakin berkembang pula tindak pembajakan. Kemampuan suatu negara untuk mengawal kapal-kapal dagang mereka dengan kapal perang untuk menghindari bajak laut sangat terbatas. Kerena itu, dikembangkanlah aturan-aturan yang 'kaku' untuk mencegah para bajak laut sebagai alat tambahan untuk mencegah terjadinya pembajakan. ${ }^{16}$ The Rhodian Sea Laws adalah percbaan pertama untuk mengkodifikasikan hukum maritim, yang berisi kebiasaan-kebiasaan

${ }^{13}$ Ibid. hlm. 96
${ }_{14}$ Yitiha Simbeye, Yitiha Simbeye, Immunity and International Criminal Law, Ashgate Publishing Limited, USA, 2004, hlm. 42

${ }^{15}$ Charles Fairman, "A Note on Piracy Jure Gentium", The American Journal of International Law, Vol. 29, No. 3, hlm. 508

${ }^{16}$ Michael J. Kelly, Loc.cit 
yang sudah lama yang diupayakan oleh orang-orang Yunani pada masa antara 800 dan 900 SM. $^{17}$

Meskipun definisi pembajakan di laut begitu beragam baik antara ahli satu dan ahli lain, maupun berubah dari masa ke masa, Belum ditemukan definisi pasti mengenai apa sebenarnya piracy, apa yang menjadi ukuran suatu kejahatan agar dapat disebut piracy, dapat disimpulkan dua karateristik dari piracy itu sendiri, yakni: ${ }^{18}$

1. Adanya suatu kekerasan, baik secara aktual maupun percobaan, terhadap hak-hak umum, baik terhadap orang maupun barang

2. Tidak ada bentuk tunduk, patuh atau kesetiaan terhadap suatu negara.

Selain dari karateristik tersebut, Dapat dikatakan bahwa perampokan adalah unsur esensial dari pembajakan. Akan tetapi untuk mendefinisikan bahwa piracy hanya semata-mata robbery dapat membuat definisi dari piracy tersebut menjadi terlalu sempit atau terlalu luas. ${ }^{19}$ Namun, disebabkan Definisi hukum pembajakan telah berfluktuasi selama berabad-abad, baru-baru ini pembajakan dilaut didefinisika sebagai "serangan kekerasan di laut". Bajak laut kontemporer pada umumnya dapat di klasifikasikan dalam dua kategori: pertama, yang beroperasi dalam skala yang kecil, dan yang kedua adalah kelompok yang terorganisir dengan baik yang biasanya tujuan nya adalah merampas kargo dari kapal para pedagang atau bertujuan merampas kapal itu sendiri.

Dengan perkembangan definisi dan konsep yang berbeda-beda mengenai piracy ini negara-negara tentu harus mempertimbangkan cara-cara untuk menyeragamkan bagaimana pendekatan terhadap piracy ini dan United Nations Convention on the Law Of the Sea (Selanjutnya disingkat UNCLOS) menjadi

\footnotetext{
${ }^{17}$ Ibid, hlm. 29

${ }^{18}$ Ibid, hlm. 35

${ }^{19}$ Charles Fairman, Op.cit, hlm. 509
}

salah satu upaya untuk dapat menyeragamkannya. Dalam UNCLOS telah dimuat mengenai definisi piracy jure gentium, yakni dalam pasal 101 yang menyatakan:

$$
\begin{aligned}
& \text { Piracy consists of any of the } \\
& \text { following acts: }
\end{aligned}
$$

a. any illegal acts of violence or detention, or any act of depredation, committed for private ends by the crew or the passengers of a private ship or a private aircraft, and directed:

$i$. on the high seas, against another ship or aircraft, or against persons or property on board such ship or aircraft;

ii. against a ship, aircraft, persons or property in a place outside the jurisdiction of any State;

b. any act of voluntary participation in the operation of a ship or of an aircraft with knowledge of facts making it a pirate ship or aircraft;

c. any act of inciting or of intentionally facilitating an act described in subparagraph (a) or (b).

Setelah uraian diatas mengenai perkembangan dan ragam definisi dari piracy, yang paling penting untuk dicatat adalah bahwa Pembajakan menurut hukum internasional (piracy jure gentium) harus dibedakan dari pembajakan menurut hukum munisipal. Kejahatan yang bisa disebut sebagai pembajakan menurut hukum munisipal belum tentu digolongkan piracy jure gentium, maka dari itu tidak termasuk dalam yurisdiksi universal. ${ }^{20}$ Dalam paper ini yang akan dibahas adalah piracy jure gentium, kejahatan pembajakan yang mengancam seluruh masyarakat internasional, bukan hanya negara tertentu saja.

\section{B. Yurisdiksi Universal dalam penegakan hukum terhadap Piracy Jure Gentium}

20 Malcolm N. Shaw QC, Hukum Internasional, (Terjemahan Derta Sri Widowatie, et. al.), Penerbit Nusa Media, Bandung, 2013, hlm. 391 
Suatu tindak pidana yang tunduk pada yurisdiksi universal adalah tindak pidana yang berada dibawah yurisdiksi semua negara dimana pun tindakan itu dilakukan. Karena umumnya diterima, tindakan yang bertentangan dengan kepentingan masyarakat internasional, maka tindakan itu dipandang sebagai delik jure gentium dan semua negara berhak untuk menangkap dan menghukum pelakupelakunya. Jelas tujuan pemberian yurisdiksi universal tersebut adalah untuk menjamin bahwa tidak ada tindak pidana semacam itu yang tidak dihukum. ${ }^{21}$

Yang termasuk dalam yurisdiksi universal salah satunya adalah kejahatan perompakan jure gentium. Piracy menjadi sesuatu yang mulai mengkhawatirkan semua bangsa ketika Romawi berkuasa. Romawi berjanji untuk memasukkan menekan pembajakan dibawah lex de provinciis praetoris pada $100 \mathrm{SM}$ dan mengharapkan kerjasama dari sekutunya. Pada masa itu pula semakin dijunjung tinggi baha bajak laut adalah musuh umat manusia, dan merupakan musuh bagi masyarakat internasional. ${ }^{22}$

Pembajakan merupakan tindak pidana pertama yang tunduk dalam yurisdiksi universal. Bahkan dapat dikatakan bahwa prinsip yurisdiksi universal lahir pertama kali disebabkan karena adanya keinginan dari negaranegara untuk menindak kejahatan pembajakan yang dilakukan di laut lepas. Dengan adanya prinsip universalitas ini setiap negara berhak untuk menangkap perompak di laut lepas dan menghukum mereka tanpa memandang kebangsaan serta tempat dilakukannya kejahatan tersebut. $^{23}$

Selain itu, Alasan munculnya prinsip universalitas adalah bahwa pelaku suatu kejahatan dianggap orang yang

21 J.G. Starke, Pengantar Hukum Internasional, edisi kesepuluh, Jakarta, Sinar Grafika, 2003, hlm. 304

${ }^{22}$ Yitiha Simbeye, Op.cit, hlm. 42

${ }^{23}$ J.G. Starke, Op.cit, hlm.305 sangat kejam, musuh seluruh umat manusia, jangan sampai ada tempat untuk pelaku meloloskan diri dari hukuman, sehingga tuntutan yang dilakukan oleh suatu negara terhadap pelaku adalah atas nama seluruh masyarakat internasional. ${ }^{24}$

Namun, Prosecuting para pembajak laut dengan pendekatan yang yurisdiksi universal ini menimbulkan beberapa isu. Secara luas telah ditegaskan oleh pengadilan dan oleh ahli hukum bahwa selama ratusan tahun yurisdiksi universal telah diterapkan pada kejahatan pembajakan (di laut). ${ }^{25}$ Akan tetapi, faktanya menurut data tentang jumlah pembajakan yang dilakukan dalam periode dua belas tahun (1998-2009) yang diperoleh dari lembaga internasional dan kelompok industri maritim, dari semua kasus pembajakan yang jelas yang dapat dihukum di bawah yurisdiksi universal, penuntutan internasional terjadi tidak lebih dari 1,47 persen. ${ }^{26}$

Tentu saja hal tersebut menjadi pertanyaan, apa yang menyebabkan penegakan bajak laut dengan menggunakan yurisdikisi universal ini dapat dikatakan kurang efektif. Penerapan yurisdiksi universal dalam hal menangkap dan menghukum para bajak laut memang telah ditegaskan dalam catatan sejarah. Namun, juga terjadi inkonsistensi dan pergeseran kebijakan-kebijakan negara terhadap pembajakan selama berabadabad. Jika ditilik kembali, pelaksanaan universal jurisdiction untuk menghukum para bajak laut selalu lebih dikombinasikan dengan pendekatan praktis yang mendefenisikan bahwa pembajakan di laut

24 Sefriani, Hukum Internasional Suatu Pengantar, Rajawali Pers, Jakarta, 2012, hlm. 244

${ }^{25}$ Matthew Garrord, "Piracy, the Protection of Vital State Interests and the False Foundations of Universal Jurisdiction in International Law", Diplomacy \& Statecraft, Vol. 25, Issue 2, 2014 (published online), hlm. 195

26 Eugene Kontorovich and Steven Art, Op.cit, hlm. 436 
adalah kejahatan dibawah hukum munisipal. ${ }^{27}$

Selain itu, sulitnya pelaksanaan yurisdiksi untiversal juga terkait masalah pembiayaan. Yurisdiksi universal memungkinkan seluruh negara memiliki wewenang untuk menangkap bajak laut diluar yurisdiksi negara-negara manapun, akan tetapi melakukan hal tersebut membutuhkan penyebaran sumberdaya angkatan laut yang signifikan. Luasnya laut lepas membuat tindakan tersebut memakan biaya yang tidak sedikit karena dibutuhkan dalam hal pembiayaan tenaga kerja dan perlengkapan-perlengkapan yang dibutuhkan, selain itu hal ini juga tentunya amat berbahaya. Sebelum adanya wabah bajak laut Somalia, tidak ada satupun negara di masa modern ini yang berniat untuk mengirimkan kapal-kapalnya ke luar wilayah mereka hanya untuk memberantas bajak laut. ${ }^{28}$

Permasalahan lain yang memungkinkan menjadi faktor mengapa pendekatan yurisdiksi universal sulit diterapkan dalam penegakan terhadap kejahatan bajak laut adalah perbedaan dari konsep penggunaan yurisdiksi universal dalam penegakan hukum terhadap bajak laut tersebut. beberapa ahli mengemukakan bahwa konsep yang disebut sebagai yurisdiksi universal dalam praktiknya adalah "prinsip perlindungan", Prinsip perlindungan memungkinkan Negaranegara di bawah hukum internasional untuk memberikan efek ekstrateritorial terhadap legislasi yang mengkriminalisasi perilaku di luar negeri, yang merupakan ancaman bagi kepentingan vital mereka. ${ }^{29}$

27 Lauren Benton, "Toward a New Legal History of Piracy: Maritime Legalities and the Myth of Universal Jurisdiction", International Journal of Maritime History, XXIII, No.1, 2011, hlm. 225

Op.cit, hlm. 450

28 Eugene Kontorovich and Steven Art,

${ }^{29}$ Matthew Garrord, Op.cit, hlm. 196
Sedangkan pada November tahun 2000 ahli hukum dan hubungan internasional terkemuka bertemu di Universitas Princeton dan atas dasar paper ilmiah ang telah disiapkan untuk agenda tersebut, dihasil kan lah The Princeton Principles on Universal Jurisdiction. Prinsip 1 (1) mendefiisikan yurisdiksi universal sebagai berikut: ${ }^{30}$

"Universal jurisdiction is criminal jurisdiction based solely on the nature of the crime, without regard to where the crime was committed, the nationality of the alleged or convicted perpetrator, the nationality of the victim, or any other connection to the state exercising such jurisdiction"

Jika dilihat dari definisi ini sepertinya telah memenuhi syarat untuk menggambarkan apa itu yurisdiksi universal, namun tentunya konsep ini sangat berbeda bahkan dapat disebut bertentangan jika menyatakan bahwa negara mengadili piracy karena adanya 'kepentingan', yang mana jelas-jelas dalam prinsip Princeton dinyatakan bahwa yurisdiksi universal tidak mendasarkan nasionalotas ataupun hubungan apapun dalam melaksanakan yurisdiksi tersebut.

Piracy jure gentium terjadi tempat dimana tidak terdapat kedaulatan teritorial suatu negara. akan tetapi perbuatan ini dipertimbangkan sebagai kejahatan yang berbahaya untu mayarakat internasional secara luas. Dalam keadaan ini, menurut yurisdiksi universal harusnya negara yang menangkap adalah negara yang berwenang mengadili para bajak laut ini, terlepas dari tidak adanya faktor keterkaitan secara tradisional dalam penuntutan bajak laut, karena jika itu dipertimbangkan maka negara tersebut bertindak atas namanya sendiri uti singulus (mengadili karena

\footnotetext{
${ }^{30}$ Peter Weiss, "Universal Jurisdiction: Past, Present and Future" , American Society of International Law, Vol. 102, 2008, hlm. 407
} 
adanya kepentingan khusus), bukan atas nama masyarakat internasional. ${ }^{31}$

Namun tentu saja, seringkali teori dan praktis adalah dua hal yang berbeda. Dalam buku Luc Reydams beliau menyatakan bahwa upaya untuk memperluas cakupan yurisdiksi universal dari hanya "most egrerious crimes", praktik nyatanya di banyak negara justru yurisdiksi universal diabaikan bahkan dianggap tidak ada sama sekali, dan beliau juga menyatakan untuk menyimpulkan bagaimana eksistensi yurisdiksi universal "the 'universal' in 'universal jurisdiction' may remain wishful thinking for a long time." 32

Pendekatan yang kurang efektif dibawah yurisdiksi universal ini tentunya membuat para ahli hukum mencari solusi lain untuk mengurangi terjadinya kejahatan bajak laut, karena piracy tentunya sangat merugikan masyarakat internasional. Mulai bermunculan solusi-solusi lain yang dirasa lebih relevan dan akan lebih efektif untuk menegakkan hukum terhadap piracy jure gentium yang dikenal di masa sekarang. Pendekatan lain tersebut diantaranya menjadikan piracy jure gentium salah satu kejahatan yang berada dibawah yurisdiksi International Criminal Court (selanjutnya disingkat ICC) dan membentuk kebijakan hukum internasional publik dalam High Level Piracy Working Group (HLPWG), yang sejak 2011 telah memproduksi memorandum tentang isu-isu utama dalam penuntutan pembajakan kontemporer. ${ }^{33}$

Solusi yang pertama adalah menjadikan piracy jure gentium salah satu kejahatan yang berada dibawah yurisdiksi ICC, solusi ini muncul karena dianggap pengadilan nasional memiliki beberapa kelemahan-kelemahan sehingga dirasa

31 Georges Abi-Saab, "The Proper Role of Universal Jurisdiction", Journal of International Criminal Justice 1, 2003, hlm. 600

32 David Stewart, "Some Perspectives on Universal Jurisdiction", American Society of International Law, Vol. 102, 2008, 405

33 Michael Scharf and Mistale Taylor, Op,cit, hlm 77 kurang efektif untuk mengadili piracy di pengadilan nasional. kelemahan pertama pengadilan nasional mungkin tidak memiliki kapasitas hukum yang cukup atau keahlian untuk mengadili kejahatan berat yang menjadi perhatian internasional. Sebagai contoh, beberapa negara tidak memiliki ketentuan legislasi yang tepat untuk menutup jenis kriminalitas bajak laut. Bahkan jika mereka lakukan, hal-hal masalah mungkin terlalu rumit untuk diproses oleh para penegak hukum pengadilan nasional, dalam hal ini polisi, jaksa, dan hakim, karena jenis kejahatan yang dilakukan adalah kejahatan yang melibatkan orang dan bukti dari lebih dari satu negara. ${ }^{34}$

Sulit bagi pengadilan nasional untuk menjunjung tinggi azas keadilan melalui suatu cara yang tidak biasa dan adil. Setiap negara memiliki cara-cara yang signifikan dalam setiap penuntutan mengenai warga negara sendiri. Pengadilan nasional mungkin tidak memiliki aturan prosedur pengadilan di negaranya untuk cukup melindungi hak asasi terdakwa. Hal-hal ini lah yang pada akhirnya mendorong lahirnya fenomena "catch and release", misalnya yang terjadi di Teluk Aden. permasalahan penangkapan bajak laut, proses penuntutannya meskipun telah tertangkap, bukan lah sesuatu yang mudah. Dalam peristiwa ini negara-negara melepaskan banyak tersangka bajak laut yang tertangkap. Negara-negara yang menangkap seringnya beralasan hal ini disebabkan karena sulitnya pembuktian, biaya untuk pemenjaraan yang panjag dan juga alasan alasan lain yang mengebabkan mereka melepaskan para bajak laut ini. ${ }^{35}$

Sebagaimana diketahui, prinsip dasar penegakan hukum internasional, termasuk penegakan hukum oleh Mahkamah Pidana Internasional adalah mendahulukan yurisdiksi nasional, dan yurisdiksi Mahkamah Pidana Internasional

\footnotetext{
${ }^{34}$ Ibid.

35 Eugene Kontorovich and Steven Art,
} 
hanyalah berlaku sebagai pelengkap (komplementer), ${ }^{36}$ jikalau terjadi "unable" (ketidakmampuan) dan "unwilling" (ketidakmauan) dari yurisdiksi pengadilan nasional Rezim komplementer atau pelengkap yang seringkali digunakan oleh Mahkamah Pidana Internasional juga cocok untuk pelanggaran pembajakan.

Di bawah rezim komplementer ini, Mahkamah Pidana Internasional dapat melaksanakan yurisdiksi dimana bangsa yang memiliki yurisdiksi atas bajak laut tersebut tidak mau ataupun tidak mampu untuk mengadili kejahatan tersebut. hal ini tentunya menjadi solusi agar tidak terjadi budaya impunitas, dimana budaya ini menyebabkan semakin maraknya kejahatan bajak laut yang merugikan masyarakat internasional.

Ada pula solusi lain yang dimulai sejak 2011, Public International Law and Policy Group (selanjutnya disingkat PILPG) mengadakan High Level Piracy Working Group (selanjutnya disingkat HLPWG) yang diketuai oleh Proffessor Michael Scarf. Kelompok kerja ini dikhususkan untuk mendiskusikan tantangan-tantangan hukum yang ditunjukkan oleh pembajakan laut modern, khususnya bagaimana cara terbaik untuk memfasilitasi penuntutan terhadap bajak laut yang telah tertangkap. ${ }^{37}$

Mandat untuk kelompok kerja ini adalah untuk menyediakan aturan dan saran kebijakan dalam cakupan domestik, kawasan, dan internasional dalam hal mekanisme piracy, dengan tujuan membentuk respon yang efektif untuk menghadapi ancaman bajak laut yang semakin berkembang. Seperti yang telah dinyatakan sebelumnya HLPWG fokus untuk memfasilitasi penuntutan terhadap bajak laut di pengadilan-pengadilan seluruh dunia, terutama terhadap bajak laut somalia. Karena meskipun dengan bantuan

\footnotetext{
Internasional

37 Michael Scharf and Mistale Taylor, Op.cit, hlm. 78
}

${ }^{36}$ Lihat Pasal 1 Statuta Mahkamah Pidana internasional yang signifikan, akan butuh waktu yang sangat lama bagi Somalia untuk menyediakan peradilan yang adil dan efektif untuk mengadili para bajak laut. $^{38}$

Karena hal tersebut, muncul lah gagasan untuk mendirikan tribunal internasional sebagai alat penuntutan dalam hal memerangi bajak laut. Gagasan ini muncul juga karena melihat dalam dua dekade terakhir, untuk menghadapi kesulitan dalam kasus-kasus kejahatan internasional, masyarakat internasional membentuk tribunal-tribunal ad hoc misalnya ICTY, ICTR, dan lain nya. Tribunal-tribunal yang telah ada sebelumnya dapat menjadi model yang berguna untuk membentuk tribunal bagi bajak laut kedepannya. ${ }^{39}$

Namun, munculnya berbagai alternatif ini tetap tidak menutup kemungkinan bahwa yurisdiksi universal masih diperlukan, Yurisdiksi universal berlaku untuk pembajakan, tepatnya karena negara-negara bendera tidak dalam posisi yang memungkinkan untuk dapat mengambil sebuah tindakan. Hal ini dikarenakan posisi bajak laut, yaitu di laut lepas, dimana untuk melakasanakan kebijakan memerlukan aset angkatan laut dengan biaya yang mahal, dan juga hal ini biasa terjadi karena negara pantai memiliki penegakan hukum yang lemah. ${ }^{40}$ Seringkali pula, saat kejahatan ini terjadi negara-negara terdekat adalah negaraneagra yang berurusan dengan konflik internal yang serius atau krisis fiskal, dan dengan demikian, negara-negara ini tidak dapat mempertahankan armada penjaga pantai yang kuat. Daerah-daerah ini tidak memiliki pengelola tempat yang efektif, menunjukkan bahwa kurangnya pengawasan terhadap alur laut. ${ }^{41} \mathrm{Jadi}$,

\footnotetext{
${ }^{38}$ Ibid, hlm. 84

${ }^{39}$ Ibid.

40 Eugene Kontorovich and Steven Art, Op.cit, hlm.447

41 Nerea Marteache and Gisela Bichler, Loc.cit
} 
yurisdiksi universal secara teori ada untuk mengisi celah dalam yurisdiksi.

\section{Kesimpulan}

Pembajakan di laut dapat dikatakan sebagai kejahatan internasional tertua dan definisinya telah berubah dari masa ke masa. Kejahatan ini adalah awal munculnya yurisdiksi universal, dimana negara-negara dalam masyarakat internasional menganggap bahwa bajak laut adalah musuh bersama umat manusia. Setelah lama tidak muncul, sekarang pembajakan di laut marak kembali. Banyak kerugian yang disebabkan oleh kejahatan tersebut. akan tetapi dari banyaknya kasus pembajakan hanya sedikit negara-negara yang melakukan penuntutan dibawah yurisdiksi universal. Hal ini memang disebabkan oleh beberapa alasan, seperti alasan pembiayaan atau tidak adanya hukum yang memadai untuk mengadili para pembajak laut tersebut. namun, tentu saja hal ini tidak dapat dibiarkan, karena ditakutkan akan muncul budaya impunitas. Maka dari itu para ahli muncul dengan alternative-alternatif lain seperti membuat tribunak khusus untuk mengadili kasus bajak laut. Akan tetapi dengan munculnya solusi-solusi ini apa berarti pelaksanaan yurisdiksi untiversal dalam hal penegakan hukum terhadap bajak laut sudah tidak dibutuhkan lagi? Pembajakan adalah sebuah kejahatan yang rumit, dikarenakan pembajakan terjadi di laut lepas yang tentu saja sangat luas. Hal ini membutuhkan kerja sama negara-negara untuk memberantasnya. Yurisdiksi universal melibatkan semua negara, semua negara berhak untuk melakukan penuntutan meskipun tidak secara langsung terkena dampaknya. Tidak ada yang menyangkal, bahwa bajak laut adalah musuh bersama umat manusia, maka dalam meminimalisirnya tentu saja butuh bantuan dari seluruh umat manusia, dalam artian seluruh negara-negara. maka dari itu, yurisdiksi universal pada konsepnya sudah cukup dan sesuai dalam hal penegakan hukum terhadap kejahatan pembajakan, akan tetapi perlu adanya kerjasama dan koordinasi antara negara-negara untuk saling membantu agar tidak terjadi budaya impunitas terhadap para bajak laut ini. 


\section{Daftar Pustaka}

Bantekas, Ilias and Susan Nash, 2003, International Criminal Law, $2^{\text {nd }}$ edition, Cavendish Publishing, Australia.

Charles Fairman, "A Note on Piracy Jure Gentium", The American Journal of International Law, Vol. 29, No. 3.

David Stewart, "Some Perspectives on Universal Jurisdiction", American Society of International Law, Vol. 102, 2008.

Eugene Kontorovich and Steven Art, "An Empirical Examination Of Universal Jurisdiction For Piracy", The American Journal of International Law, Vol. 104, No. 3, 2010.

Georges Abi-Saab, "The Proper Role of Universal Jurisdiction", Journal of International Criminal Justice 1, 2003.

Nerea Marteache and Gisela Bichler, 2017, Crime Prevention and Transportation System in Crime Prevention, CRC Press, New York.

Sam Bateman, 2007, "Outlook; The New Threat of Maritime Terrorism" in Lloyd's Marine Intelligence Unit, Violace at Sea, Routledge, USA.

Sefriani, 2012, Hukum Internasional Suatu Pengantar, Rajawali Pers, Jakarta.

Shaw, Malcolm N, 2013, Hukum Internasional, (Terjemahan Derta Sri Widowatie, et. al.), Penerbit Nusa Media, Bandung.

Simbeye, Yitiha, 2004, Immunity and International Criminal Law, Ashgate Publishing Limited, USA.

Soekanto, Soerjono dan Sri Mamudji, 2003, Penelitian Hukum Normatif, Suatu Tinjauan Singkat, PT. Raja Grafindo, Jakarta.

Starke, J.G., 2003, Pengantar Hukum Internasional, edisi kesepuluh, , Sinar Grafika, Jakarta

Lauren Benton, "Toward a New Legal History of Piracy: Maritime Legalities and the Myth of Universal Jurisdiction", International Journal of Maritime History, XXIII, No.1, 2011.

Matthew Garrord, "Piracy, the Protection of Vital State Interests and the False Foundations of Universal Jurisdiction in International Law", Diplomacy \& Statecraft, Vol. 25, Issue 2, 2014 (published online). 
Michael J. Kelly, "The Pre-History of Piracy as a Crime \& Its Defitional Odyssey", Case Western Reserve Journal of International Law, Vol. 46, Issues $1 \& 2,2013$.

Michael Scharf and Mistale Taylor, "A Contemporary Approach to the Oldest International Crime", Utrecht Journal Of International and European Law.

Peter Weiss, "Universal Jurisdiction: Past, Present and Future" , American Society of International Law, Vol. 102, 2008.

Rome Statute of the International Criminal Court United Nations Convention on the Law of the Sea 1982 